\title{
Foreword
}

\section{Mathematical Chemistry. Look Back and Beyond.}

The Society of Computer Chemistry Japan is a small society with less than four hundred members but composed of hard-boiled ab initioists, alert chemo-informaticians, snobbish mathematical chemists, enthusiastic chemical educators and propagandists, etc. However, we are proud of holding two annual meetings, in spring and autumn, and publishing bimonthly journal, which can freely be downloaded.

This time hinted by Umpei Nagashima the guest editor, Haruo Hosoya, chose a very controversial theme for a special issue: Mathematical Chemistry. Look Back and Beyond. Although we did not have enough time for editing, we can proudly disseminate this issue full of vivid essays by the pioneers of mathematical chemistry. The readers will realize that the history of chemical science cannot be handed down without the proper description of the achievements of mathematical chemistry.

We, the editors know that among the readers of this issue there must be a variety of opinions and discussions of pros and cons regarding this half scientific and half philosophical problem. Please, send us your contribution in any form to JCCJ including its international edition. All of you are welcome. We, with a variety of potential referee corps, are waiting for you.

Guest editor of the special issue: Mathematical Chemistry.

Look Back and Beyond.

Haruo HOSOYA

President of the Society of Computer Chemistry, Japan

which was recently expanded to publish International Editions

(See our home page).

Journal of Computer Chemistry, Japan

https://www.jstage.jst.go.jp/browse/jccj

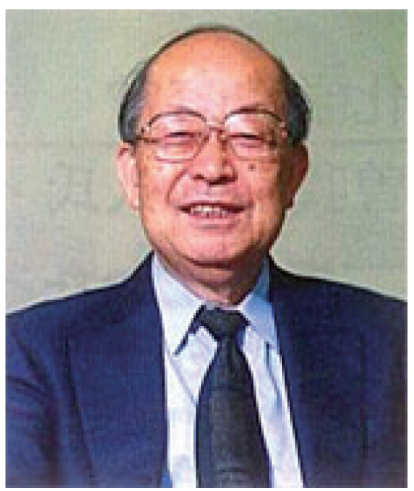

Journal of Computer Chemistry, Japan -International Edition

https://www.jstage.jst.go.jp/browse/jccjie/ 